\title{
Newly-discovered muscle in the larva of Patella coerulea (Mollusca, Gastropoda) suggests the presence of a larval extensor
}

\author{
Peter Damen and Wim J.A.G. Dictus \\ Department of Experimental Zoology, Utrecht University, Padualaan 8, 3584 CH Utrecht, Netherlands, \\ W.J.A.G.Dictus@bio.uu.nl
}

Key words: Patella, Gastropoda, Mollusca, development, larva, muscle, antagonist, cell-lineage

\begin{abstract}
The development of the muscular system of the gastropod mollusc Patella has been thoroughly studied. As a result, two larval retractors, the main and accessory larval retractor, had been described in the larva of Patella. These muscles were supposed to be responsible for the retraction of the larval body into the shell. Previously no larval extensors, which would be responsible for the extension of the larval body out of the shell, have been described. Using cell-lineage tracer injection and phalloidin staining of muscles, a newly-discovered muscle is herein identified in the larva of Patella coerulea. A functional model is presented in which two muscles are responsible for the extension of the larva, the newly-discovered muscle together with the previously recognized but inaccurately named accessory larval retractor. In our model, the latter muscle does not seem to function as a retractor but rather as an extensor.
\end{abstract}

\section{Contents}

Introduction 27

Materials and Methods $\quad 39$

Results

Discussion

Acknowledgements

References

\section{Introduction}

For many decades, the gastropod mollusc Patella has been used as a model system to study various aspects of early development. For instance, the celllineage has been described by Patten (1886), Wilson (1904), Smith (1935), van den Biggelaar (1977), and Dictus and Damen (1997). The formation of the 3D-macromere, which acts as an organizer and is responsible for the correct dorsoventral patterning of the embryo, has been described by e.g. van den Biggelaar and Guerrier (1979), Arnolds et al. (1983), Verdonk and van den Biggelaar (1983), Martindale et al. (1985), and Damen and Dictus (1996). The analysis of gene function during early development has been described by van der Kooij et al. (1996, 1998), Damen et al. (1994), Damen and van Loon (1996), Klerkx et al. (2001), Lartillot et al. (2002), Lespinet et al. (2002), Nederbragt et al. (2002a, b, c), and Wanninger and Haszprunar (2001). The formation of the musculature has been described by Smith (1935), Crofts (1955), and Wanninger et al. (1999).

In the first half of the previous century, Smith (1935) and Crofts (1955) studied muscle morphogenesis in Patella with the use of a traditional technique, i.e. microscopical observation of serial sections. Much later, Wanninger et al. (1999) studied the formation of the musculature in the larva of Patella using a much more recently introduced technique. They stained larvae of Patella with fluorescently-labeled phalloidin, which binds to F-actin, in order to visualize the musculature using confocal laser scanning microscopy (CLSM). With this technique, muscle development can be analyzed at a much higher resolution and even enables a threedimensional analysis of muscle localization. Using CLSM, Wanninger et al. (1999) showed that the formation of the principal larval and adult muscles in Patella takes place between about 28 and $52 \mathrm{~h}$ 


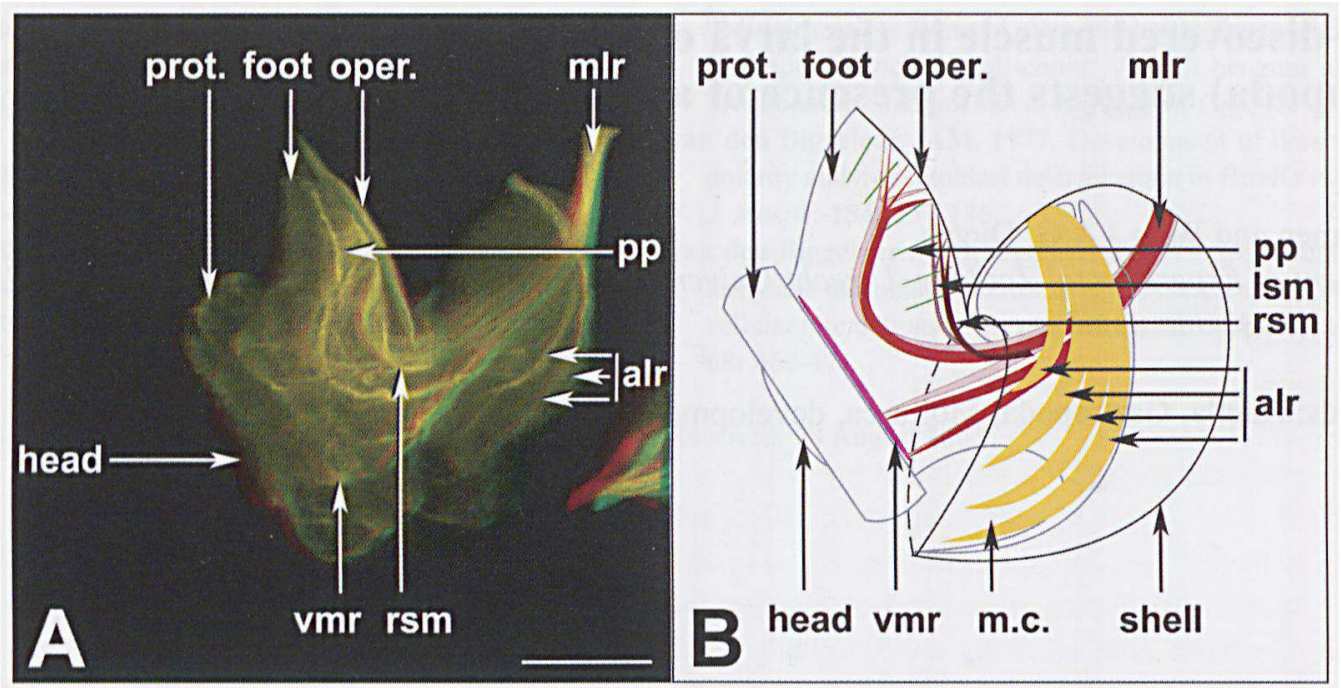

Fig. 1. Post-torsional, $50 \mathrm{~h}$ old relaxed larva in which the muscles that are visible at this stage are shown. Right-lateral view. (A) Stereo image. Phalloidin labeling. (B) Schematic drawing of A. In this schematic drawing and the schematic drawings that follow the muscles are drawn with different colors. For clarity, one part of the muscles is drawn with saturated colors and the other part of the muscles with the corresponding pastel colors, except the accessory larval retractor, pedal plexus and the velum muscle ring, which are drawn in saturated colors. alr = accessory larval retractor (yellow); lsm = left adult shell muscle (pastel brown); m.c. = mantle cavity; $\mathrm{mlr}=$ main larval retractor $(\mathrm{red}) ;$ oper. = operculum; $\mathrm{pp}=$ pedal plexus (green); prot. = prototroch; $\mathrm{rsm}=$ right adult shell muscle (saturated brown); vmr = velum muscle ring (pink). Scale bar: $50 \mu \mathrm{m}$. All stereo images should be examined with red-green stereo glasses in order to see the three dimensional localization of the structures shown.

after first cleavage. The muscles they described are the main larval retractor, the accessory larval retractor, the velum muscle ring, the pedal plexus and the anlagen of the left and right adult shell muscles (Fig. 1). Detailed comparison of both approaches demonstrates that the traditional approach of Smith (1935) and Crofts (1955) is quite prone to misinterpretations and even may result in missing certain details of muscle formation.

The 48 to $52 \mathrm{~h}$ old post-torsional larva of $\mathrm{Pa}$ tella is a well-developed larva with a head, a foot, a shell and a prototroch (Fig. 1). It is capable of retraction into its larval shell. The main larval retractor and the accessory larval retractor are supposed to be responsible for this process, although this has not been stated explicitly for Patella (Wanninger et al., 1999). Besides retraction, the animal must be able to extend out of its larval shell. Despite that the larva is obviously able to do so, neither muscles nor other mechanisms responsible for this action have been described in the literature.

As part of a larger study (Damen and Dictus, submitted) various early cleavage-stage blastomeres, viz., 2b, 3a, 3b, 3c, 3d, 3A, 3B, 3C, 4d and 4D, of
Patella coerulea were injected with a fluorescent marker to study their cell-lineage. Injection of one of the blastomeres, the $2 \mathrm{~b}$-micromere, resulted in labeling of an unknown bundle of fibers in 48 to $52 \mathrm{~h}$ old post-torsional larvae. After injection of the 3a- and 3b-micromeres small parts of this bundle of fibers were labeled as well. Since this unknown bundle of fibers strongly resembled a muscle, 48 to $52 \mathrm{~h}$ old post-torsional larvae were stained with fluorescently-labeled phalloidin. In a number of these larvae, besides the muscles described above, the unknown bundle of fibers was labeled as well, demonstrating that the unknown fibers are indeed muscle fibers.

Based on its location and orientation, together with the fact that no explanation for the extension of the larva out of its shell is given in the literature, it is hypothesized that the newly-discovered bundle of muscle fibers is involved in the extension of the larval body out of the shell. A hypothetical model is presented in which the newly-discovered muscle, together with the accessory larval "retractor", are responsible for the extension of the larval body out of the shell. As a result, these two muscles 
form the antagonists of the main larval retractor.

Reanalysis of literature data suggests that a structure similar to the previously undescribed muscle, and thus a potential larval extensor, is present in at least one other gastropod and that the previously undescribed muscle is homologous to the circular muscle fibers in the Müllers larva of the platyhelminth Hoploplana.

\section{Materials and methods}

\section{Obtaining embryos}

Adult specimens of the limpet Patella coerulea (Mollusca, Gastropoda) were obtained from the Mediterranean coast near Trieste (Italy) and near Banyuls-sur-Mer (France). Embryos were obtained as described before (van den Biggelaar, 1977; Damen and Dictus, 1996; Dietus and Damen, 1997). Before injection of cell-lineage tracer, embryos were treated with acidified MPFSW (pH 3.9) for 2-3 min to remove the surrounding jelly layer. Embryos that were not injected but only cultured to stain the musculature with phalloidin were also dejellied. To reduce microbial infection, embryos were usually transferred to antibiotic-containing MPFSW ( $60 \mathrm{mg}$ penicillin $\mathrm{G}$ and $50 \mathrm{mg}$ streptomycin per liter MPFSW) about 6 to $7 \mathrm{~h}$ after first cleavage. Some embryos were cultured in the absence of antibiotics. During culturing and all experimental procedures embryos and larvae were kept at 17 to $18^{\circ} \mathrm{C}$.

\section{Cell-lineage, quadrant identification and cell-lineage tracer injection}

The early development and cell-lineage of Patella have been described before (see e.g., Wilson, 1904; Smith, 1935; van den Biggelaar 1977; Dictus and Damen, 1997). The nomenclature employed is that of Wilson (1892) and Conklin (1897). For clarity, figure 2 shows some stages of the development of Patella.

The cell-lineage tracer tetramethylrhodamine dextran (MW $10,000 \mathrm{Da}, \mathrm{D}-1868$, Molecular Probes Europe, Leiden, Netherlands; TMR-dextran) was injected using high pressure-injection as described previously (Damen and Dictus, 1994; Dictus and Damen, 1997). TMR-dextran was dissolved at a concentration of $10 \%(w / v)$ in aqua dest or in injection buffer $(10 \mathrm{mM}$ Hepes, $150 \mathrm{mM} \mathrm{KCl}, 1 \mathrm{mM} \mathrm{CaCl}, 10$ mM EGTA, pH 7.0).

Blastomeres, viz., 2b, 3a, 3b, 3c, 3d, 3A, 3B, 3C, 4d and 4D, were injected at specific stages of develópment. For instance, the 2b-micromere was injected at the 16-cell stage. Embryos of Patella are radially symmetrical up to about $60 \mathrm{~min}$ after the fifth cleavage (32-cell stage). Therefore, quadrant identity (A-, B-, C-, or D-quadrant) cannot be determined until after this moment (van den Biggelaar 1977; van den Biggelaar and Guerrier, 1979; Damen and Dictus, 1996). By analyzing injected larvae retrospectively, the identity of injected blastomeres was determined and embryos in which the $2 \mathrm{~b}$-micromere was injected were identified. The $3 \mathrm{a}-$ and $3 \mathrm{~b}$-micromeres were injected at the 32-cell stage. Since at about $60 \mathrm{~min}$ after fifth cleavage embryos are still at the 32-cell stage, and the quadrants can be denominated at this stage, 3a- and $3 \mathrm{~b}$-micromeres could be identified before injection.

\section{Selection and fixation}

Abnormal larvae at 48 to $52 \mathrm{~h}$ after first cleavage, i.e., larvae that do not possess eyes, a prototroch, a shell, a foot and an operculum or that are not able to retract into their shell, were discarded. The muscles of normal larvae of 48 to $52 \mathrm{~h}$ after first cleavage were relaxed by adding drops of $0.75 \mathrm{M} \mathrm{MgCl}$ to the MPFSW. Subsequently, the larvae were fixed in $4 \%$ formaldehyde in $0.1 \mathrm{M}$ phosphate buffer $(\mathrm{pH} 7.4)$ for $1 \mathrm{~h}$ and rinsed in buffer (3 times for $10 \mathrm{~min}$ ).

\section{Phalloidin staining and mounting}

In order to visualize the musculature, most of the fixed larvae were stained with fluorescently-labeled phalloidin (Alexa Fluor 488 phalloidin, 300 U, A-12379, Molecular Probes Europe, Leiden, Netherlands), that binds to F-actin (modified after Wanninger et al, 1999). Laryae were permeabilized for $1 \mathrm{~h}$ in $0.1 \mathrm{M}$ phosphate buffer (pH 7.4) to which $0.2 \%$ (v/v) Triton X-100 was added to allow penetration of phalloidin. A stock solution of phalloidin was prepared by dissolving one vial of Alexa Fluor 488 phalloidin (300 U) in $1.5 \mathrm{ml}$ methanol. This stock solution was kept at $-20^{\circ} \mathrm{C}$. Some 5 or $10 \mu \mathrm{l}$ of the stock solution were put in a small glass petri dish and the methanol was allowed to evaporate. Larvae were taken in $200 \mu \mathrm{l}$ of the $0.1 \mathrm{M}$ phosphate buffer ( $\mathrm{pH} 7.4$ ) to which $0.2 \%$ Triton X-100 was added and put on the dry phalloidin. The petri dish was gently shaken to dissolve the dried phalloidin after which the larvae were incubated for 1 h. Subsequently, the larvae were washed in $0.1 \mathrm{M}$ phosphate buffer ( 3 times for $10 \mathrm{~min}$ ) and dehydrated in a graded series of ethanol $(70 \%, 80 \%, 90 \%, 96 \%, 100 \%, 100 \%, 100 \%$; each step 5 min). After transferring the larvae to a 1:1 (v/v) mixture of ethanol and Murray's ( $1: 2 \mathrm{v} / \mathrm{v}$ benzylalcohol and benzylbenzoate), they were mounted in convex polished slides in Murray's to which $0.1 \%$ of the antifading agent $n$-propyl gallate (Sigma, St. Louis, Mo, USA) was added.

\section{Confocal laser scanning microscopy (CLSM)}

All larvae were observed in a Leica upright confocal laser scanning microscope [Leica DM-RBE (microscope), Leica TCSNT (confocal laser), Leica, Heidelberg, Germany]. One, or in most cases two or even three z-series were recorded at different angles. All z-series consisted of 72 images and were transformed into stereo images that were analyzed with a pair of red-green stereo glasses. 


\section{Results}

\section{Fluorescent cell-lineage tracer injection}

Early cleavage-stage blastomeres, viz., $2 \mathrm{~b}, 3 \mathrm{a}, 3 \mathrm{~b}$, $3 \mathrm{c}, 3 \mathrm{~d}, 3 \mathrm{~A}, 3 \mathrm{~B}, 3 \mathrm{C}, 4 \mathrm{~d}$ and $4 \mathrm{D}$, were injected as part of a large study to trace the cell-lineage of the musculature in Patella coerulea (Damen and Dictus, submitted). Figure 2 shows drawings of early cleavage-stage embryos in which the localization of some injected blastomeres is indicated. Injection into one of these blastomere, the 2b-micromere (yellow in Fig. 2A), resulted in a complex pattern of labeling in 48 to $52 \mathrm{~h}$ old post-torsional larvae (Fig. 3). Analysis with CLSM and the subsequent analysis of z-series revealed two large, ciliated prototroch cells and a ring of fluorescent cells that bordered the prototroch at the post-trochal side (Fig. 3A). Medially, a strand of cells was labeled. This strand ran from a ventral position, between the two labeled main prototroch cells, in a dorsal direction towards the dorsal side of the prototroch and curved in a posterior direction towards a position near the visceral mass (Fig. 3). Adjacent to this strand, other cells were labeled at the level of the prototroch. In addition, some labeling was seen on the inside of the right-lateral side of the shell. Most prominently labeled was a post-trochally located transverse band of fibers that was connected to the lateral shell walls. This band of fibers was U-shaped with the base of the $U$ at the ventral side of the larva. This transverse-oriented band of fibers strongly resembled muscle fibers. After injection of cell-lineage tracer into the 3a- and 3b-micromeres (yellow in Fig. 2B), small areas in the right, respectively the left part of the U-shaped transverse band of fibers were labeled as well (results not shown).

\section{Phalloidin staining}

In order to verify whether the transverse-oriented structure formed from the progeny of the $2 \mathrm{~b}$-micromere is indeed a muscle, 48 to $52 \mathrm{~h}$ old larvae were stained with phalloidin and analyzed. The fluorescence of the main larval retractor, accessory larval retractor, pedal plexus, velum muscle ring, and the anlagen of the left and right adult shell muscles was clearly visible. In addition, an unknown muscle was detected (Fig. 4). The morphology of this muscle was exactly like that of the other muscles, although the phalloidin staining of this unknown muscle was weaker. This newly-discovered muscle is located between the two lateral shell walls and is U-shaped. The base of the " $U$ " is located near

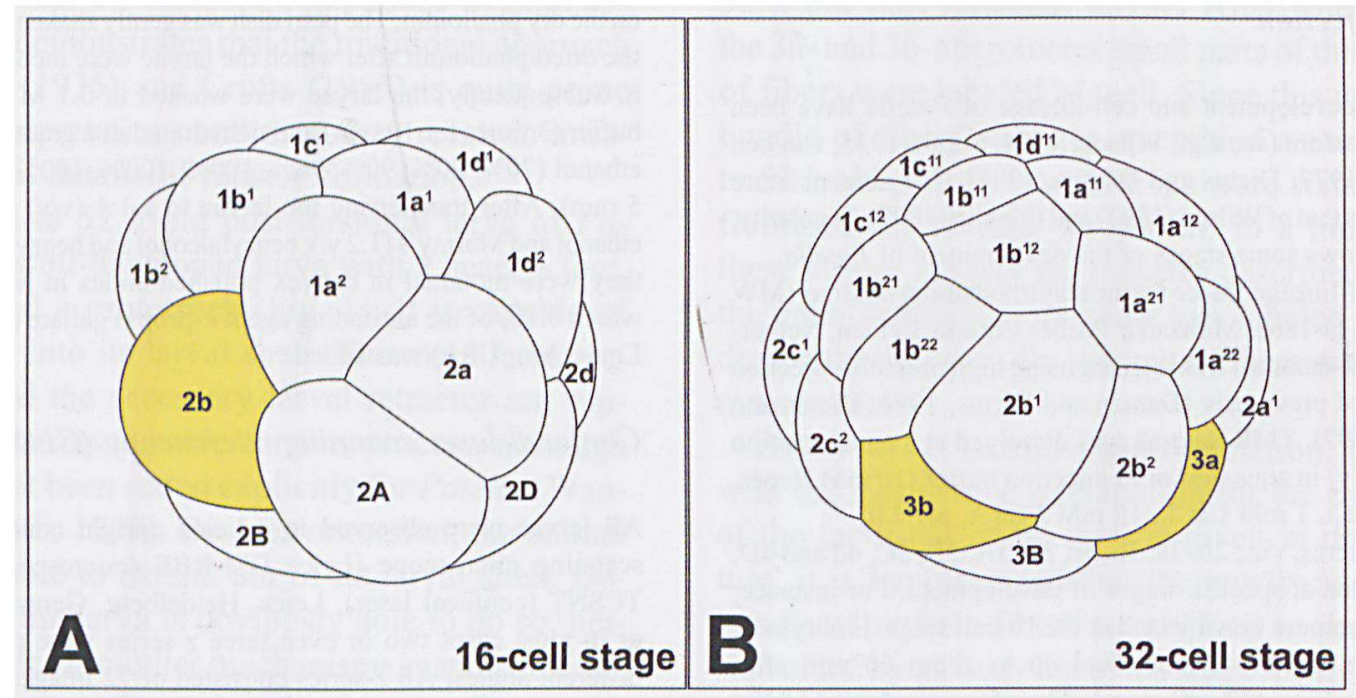

Fig. 2. Schematic drawings of several sfages in the development of Patella, modified after van den Biggelaar (1977). (A) Lateral view of a 16-cell stage embryo. The first quartet micromeres (1a-ld) have divided and the second quartet micromeres are formed (2a-2d). (B) Lateral view of a 32-cell stage embryo. In this view the first (1a-1d progeny), second (2a-2d progeny) and third (3a-3d) quartet micromeres as well as the third generation macromeres (3A-3D) are visible. 


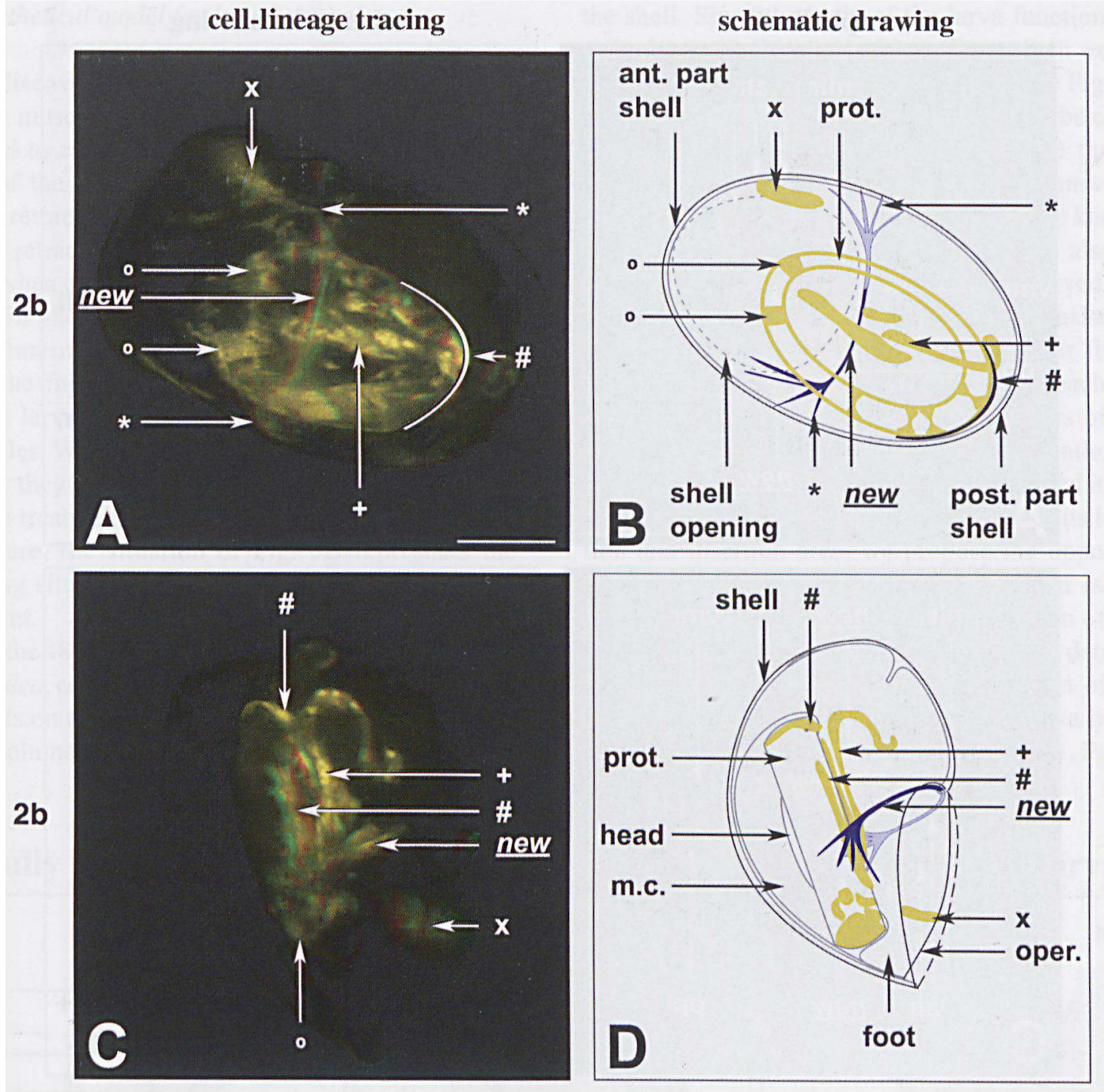

Fig. 3. Stereo images and schematic drawings of a $48 \mathrm{~h}$ old post-torsional larva that is retracted in its shell and in which the $2 \mathrm{~b}$ progeny are labeled. (A) Stereo image showing the fluorescence of the cell-lineage tracer. Animal view. Amongst other structures, a post-trochally located transverse band of fibers $(\underline{n e w})$ is labeled that is connected to the lateral shell walls $\left({ }^{*}\right)$. (B) Schematic drawing of A. (C) Stereo image of the same larva showing the fluorescence of the cell-lineage tracer. Left-lateral view. (D) Schematic drawing of $\mathrm{C} .^{*}=$ attachment of the transverse band of fibers to the shell; ${ }^{\circ}=$ large, ciliated prototroch cells; $\mathrm{x}=$ labeling on the inside of the right-lateral side of the shell; \# = ring of cells bordering the prototroch at the post-trochal side; $+=$ medially located strand of cells; ant. $=$ anterior; post. $=$ posterior. For rest of legend see figure 1 . Scale bar: $50 \mu \mathrm{m}$.

the hinge of the operculum. The fluorescence of this muscle co-localized with the fluorescence of the transverse-oriented band of fibers observed after tracing the $2 \mathrm{~b}$-progeny with TMR-dextran.

\section{Discussion}

\section{Newly-discovered muscle}

The results above describe a hitherto unknown structure in the 48 to $52 \mathrm{~h}$ old post-torsional larva of - Patella coerulea that strongly resembles a muscle. 

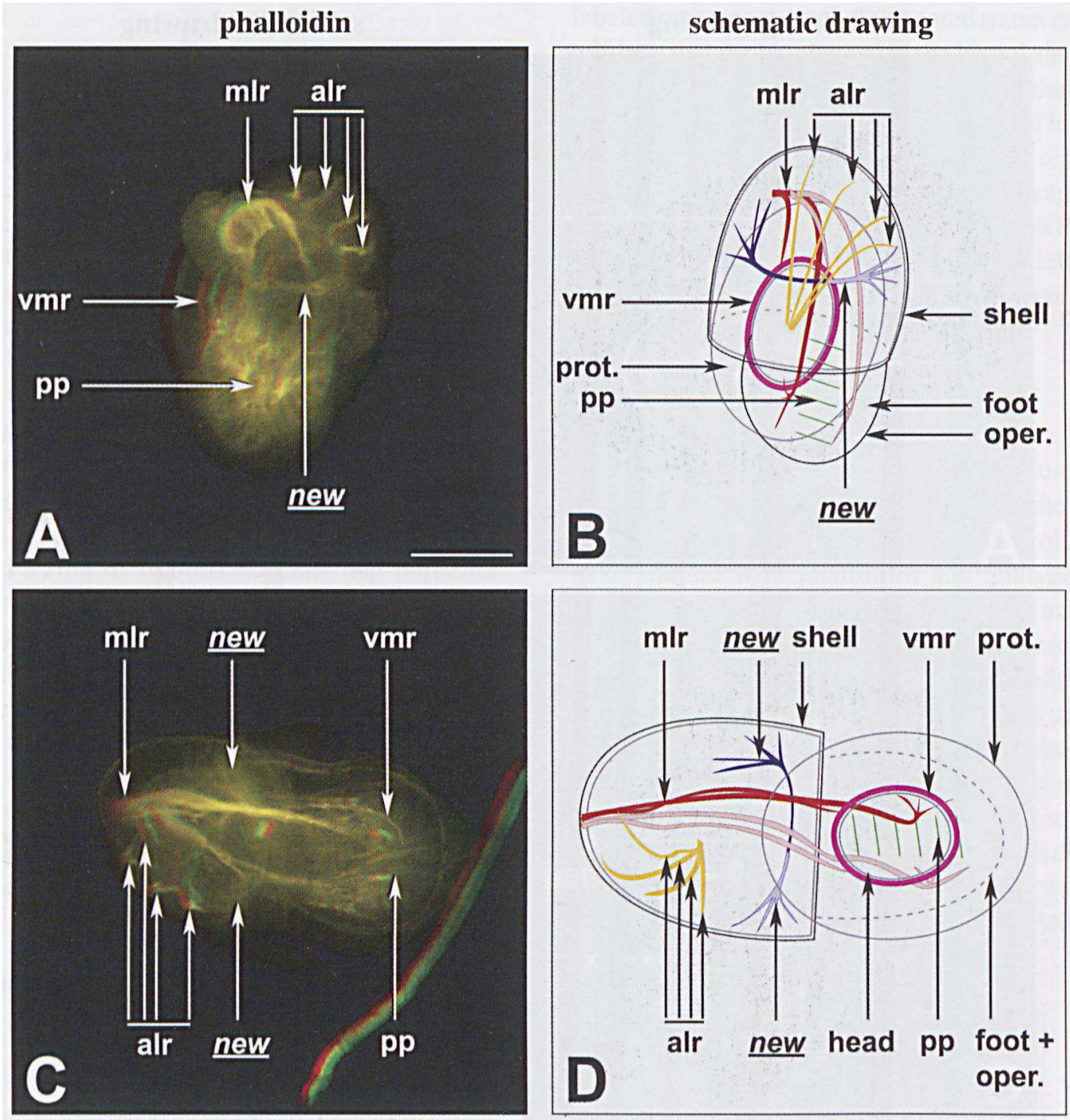

Fig. 4. Stereo images and schematic drawings of 48 to $52 \mathrm{~h}$ old larvae stained with fluorescently-labeled phalloidin. ( A) Stereo image. Ventral view of a $56 \mathrm{~h}$ old post-torsional larva. Phalloidin staining. The unknown muscle is clearly visible (new). In the right side of the larva, the four fibers of the accessory larval retractor (alr) are visible. (B) Schematic drawing of A. (C) Stereo image. Animal view of a $48 \mathrm{~h}$ old post-torsional larva. Phalloidin staining. The unknown muscle (new) is located perpendicular to and ventrally of the main larval retractor. The four fibers of the accessory larval retractor, located in the right side of the larva, are indicated as well. (D) Schematic drawing of C. For legend see figure 1. Scale bar: $50 \mu \mathrm{m}$.

Based on the morphology, the positive staining with phalloidin, and the resemblance to muscle fibers, it is concluded that the structure is indeed a muscle. Based on its location, this muscle has been named transverse muscle.

Analysis of cell-lineage data demonstrates that the transverse muscle is derived from the $2 b-\mathrm{mi}-$ cromere. In addition, the $3 \mathrm{a}-$ and $3 \mathrm{~b}$-micromeres form small parts of the transverse muscle. In contrast to the other muscles in phalloidin-stained larvae, the transverse muscle exhibited weaker staining. This indicates that these muscle fibers are not so heavily filled with F-actin containing myofibrils, and this may explain why the transverse muscle has not been observed before by Smith (1935), Crofts (1955), and Wanninger et al. (1999). 


\section{Hypothetical model for larval extension}

The discovery of an undescribed muscle, the transverse muscle, allows us to present a hypothetical model to explain the extension of the larval body out of the larval shell (Fig. 5). Fig. 5A shows a fully retracted larva with a closed operculum. The larva retracts into its shell and closes the operculum when it is disturbed, e.g. by "teasing" the larva. Fig. 5B shows a larva that is partly retracted. This is an intermediate state between the fully extended and the fully retracted state that is also obtained when larvae are treated with $\mathrm{MgCl}_{2}$ to relax the muscles. When larvae are left undisturbed for some time, they can become fully extended (Fig. 5C). Since treatment with $\mathrm{MgCl}_{2}$ immobilizes the musculature, the situation of Fig. $5 \mathrm{~B}$ represents the resting situation in which no muscular activity is present.

In the 48 to $52 \mathrm{~h}$ old post-torsional larva of Patella coerulea, contraction of the transverse muscle, which inserts on the two lateral shell walls, will decrease the volume that the larval body can occupy within the shell. Since the body of the larva functions as a 'hydrostatic skeleton', this will result in extrusion of the larval body out of the shell (see Fig. 5). The function of the transverse muscle may be compared to squeezing meat out of a sausage that is opened on one side. In addition to the transverse muscle, we think that the muscle previously known as the accessory larval retractor (alr) may also be involved in the extension process. We observed that the so-called accessory larval retractor consists of four fibers (see Fig. 1A and 4C). All four fibers reached far into the mantle and did not reach the pedal region or the velum. Since the fibers of the accessory larval retractor all end in the mantle, the accessory larval retractor cannot be involved in the retraction process of the larva. Because of its location and insertion area, we propose the opposite: the accessory larval retractor is involved in the extension process of the larva. Observation of numerous partly and fully extended larvae demonstrated that in these larvae the greater part of the shell is empty, i.e., not filled with the larva body. This can also be seen in various papers, e.g., Patten

\section{fully retracted larva}

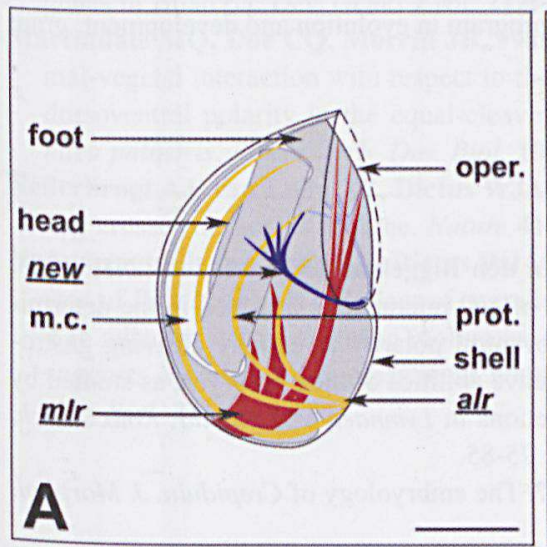

partly retracted larva

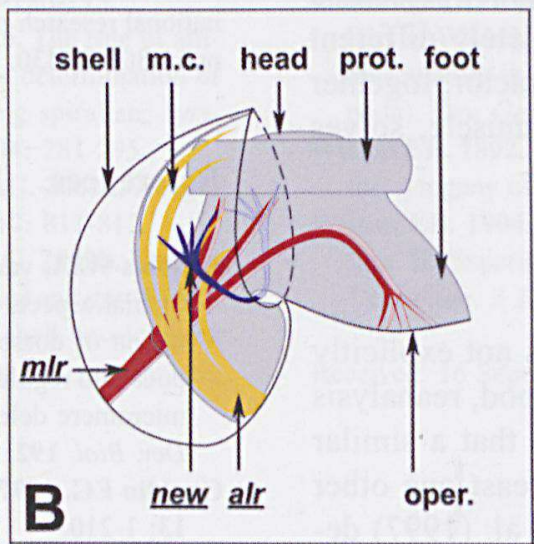

fully extended larva

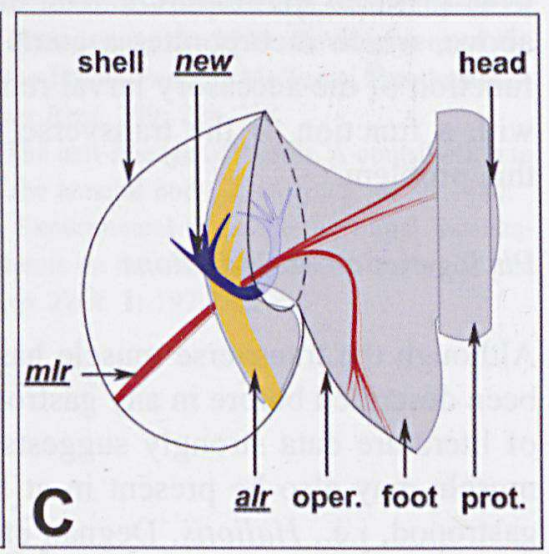

Fig. 5. Hypothetical model explaining the extension of the larval body out of the larval shell. In this model, the main larval retractor (mlr) pulls the larval body back into the shell. The accessory larval retractor (alr), together with the transverse muscle (new), are the antagonists of the main larval retractor and are responsible for the extension of the larval body out of the shell. Note that in the schematic drawings only the muscles involved in retraction and extension are depicted. The gray area represents the larval body that functions as a 'hydrostatic skeleton'. (A) Fully retracted larva. The main larval retractor $(\underline{m l r})$ is contracted. The accessory larval

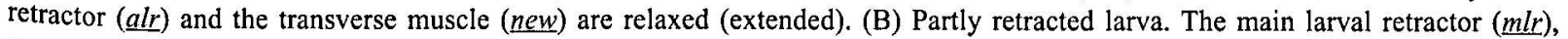
accessory larval retractor $(\underline{a l r})$, and the transverse muscle $(\underline{n e w})$ are all partly contracted. In this intermediate state, the main larval retractor $(\underline{m l})$ ) on the one hand, and the accessory larval retractor $(\underline{a l r})$ and the transverse muscle $(\underline{n e w})$ on the other hand, are in equilibrium. (C) Fully extended larva. The main larval retractor $(\underline{m l} r)$ is relaxed (extended). The accessory larval retractor $(\underline{a l r})$ and the transverse muscle ( $\underline{\text { new }})$ are contracted. For legend see figure 1. Scale bar: $50 \mu \mathrm{m}$. 
(1886), Crofts (1955), and Wanninger et al. (1999). In Fig. 5 [compare to e.g., Fig. $3 \mathrm{~A}$ in the paper of Wanninger et al. (1999)], the insertion area of the accessory larval retractor at the larval shell is visible. Since the fibers of the accessory larval retractor insert ventrally on the shell and project into the mantle, and the mantle is connected to the rim of the shell, contraction of the accessory larval retractor will result in extrusion of the larval body out of the shell. Since we expect that the accessory larval retractor is responsible for the major displacement of the larval body out of the shell, this muscle fulfills the function of a main larval extensor. The transverse muscle, which is expected to play a moderate role in the displacement of the larval body, fulfills the function of an accessory larval extensor. As a result, these two muscles form the antagonists of the main larval retractor. According to this model, the accessory larval retractor should be renamed the main larval extensor, whereas the transverse muscle may also be called the accessory larval extensor. Since no accessory larval retractor is present in this model, the main larval retractor may be renamed larval retractor.

Until now, no satisfactorily explanation for the extension of the larval body out of the shell has been given in the literature. The model presented above, which incorporates a completely different function of the accessory larval retractor, together with a function of the transverse muscle, solves this problem.

\section{Phylogenetic considerations}

Although the transverse muscle has not explicitly been described before in any gastropod, reanalysis of literature data strongly suggests that a similar muscle may also be present in at least one other gastropod, i.e., Haliotis. Degnan et al. (1997) described the musculature of the Haliotis larva using BODIPY-phallacidin. In their figure 1D, fibers are visible at the exact location where the transverse muscle is expected to be located. These fibers more or less radiate from a point between the foot and the visceral mass, close to the hinge of the operculum. These fibers are not named in the paper of Degnan and associates (1997) but may very well be the fibers of the transverse muscle. Future in- vestigations will have to provide evidence that the transverse muscle is indeed a larval extensor and whether a transverse muscle is a universal muscle in gastropods or is only present in some species.

In Patella coerulea, the transverse muscle is almost entirely formed from the progeny of the $2 \mathrm{~b}$ micromere. The circular muscle fibers in the Müllers larva of the platyhelminth Hoploplana are also derived from the 2b-micromere (Henry et al., 2000). Possibly these circular muscle fibers are homologous to the transverse muscle of Patella coerulea. Further ontogenetic research, especially in species located in a phylogenetic position between the platyhelminths and the gastropods, can shed more light on the possible homology of the circular muscle fibers in Hoploplana and the transverse muscle in Patella coerulea.

\section{Acknowledgements}

The authors wish to thank H.A. Wagemaker for his technical assistance and the staff from the aquarium for taking care of the limpets. Last but not least, Mr. W.J. Hage is thanked for his assistance with the CLSM. P.D. was supported by the Earth and Life Sciences foundation (ALW), which is subsidized by the Netherlands Organisation for Scientific Research (NWO), the Netherlands. This is publication number 19 of the Dutch national research program in evolution and development, grant num, 805.33.430.

\section{References}

Arnolds WJA, van den Biggelaar JAM, Verdonk NH. 1983. Spatial aspects of cell interactions involved in the determination of dorsoventral polarity in equally cleaving gastropods and regulative abilities of their embryos, as studied by micromere deletions in Lymnaea and Patella Roux's Arch. Dev, Biol. 192: 75-85.

Conklin EG. 1897. The embryology of Crepidula. J. Morphol. 13: 1-210.

Crofts DR. 1955. Muscle morphogenesìs in prìmitîve gastropods and its relation to torsion. Proc. Zool. Soc. Lond. 125: 711-750.

Damen P, Dictus WJAG. 1994. Cell lineage of the prototroch of Patella vulgata (Gastropoda, Mollusca). Dev Biol. 162: 364-383.

Damen P, Dictus WJAG. 1996. Organiser role of the stem cell of the mesoderm in prototroch patterning in Patella vulgata (Mollusca, Gastropoda). Mech. Dev 56: 41-60.

Damen P, Dictus WJAG. (submitted) Origin of mesoderm in the mollusc Patella. 
Damen WG, van Loon AE. 1996. Multiple cis-acting elements act cooperatively in directing trochoblast-specific expression of the alpha-tubulin-4 gene in Patella embryos. Dev. Biol. 176: 313-324

Damen WG, van Grunsven LA, $\operatorname{van}_{x}$ Loon AE. 1994. Transcriptional regulation of tubulin gene expression in differentiatîng trochoblasts during early development of Patella vulgata. Development 120: 2835-2845.

Degnan BM, Degnan SM, Morse DE. 1997. Muscle-specific regulation of tropomyosin gene expression and myofibrillogenesis differs among muscle systems examined at metamorphosis of the gastropod Haliotis rufescens. Dev. Genes Evol. 206: 464-471.

Dictus WJAG, Damen P. 1997. Cell-lineage and clonal-contribution map of the trochophore larva of Patella vulgata (Mollusca). Mech. Dev, 62: 213-226.

Henry JQ, Martindale MQ, Boyer BC. 2000. The unique developmental program of the acoel flatworm, Neochildia fusca. Dev. Biol. 220: 285-295.

Klerkx AHEM, de Boer E, van Loon AE. 2001. Spatio-temporal expression of a gene encoding a putative RNA-binding protein during the early larval development of the molluse Patella vulgata. Dev. Genes Evol. 211:423-427.

Lartillot $\mathbf{N}$, Lespinet $\mathrm{O}$, Vervoort $M$, Adoutte A. 2002. Expression pattern of Brachyury in the mollusc Patella vulgata suggests a conserved role in the establishment of the AP axis in Bilateria. Development 129: 1411-21.

Lespinet $\mathbf{O}$, Nederbragt AJ, Cassan M, Dictus WJAG, van Loon AE, Adoutte A. 2002. Characterisation of two Snail genes in the gastropod mollusc Patella vulgata. Implications for understanding the ancestral function of the snail-related genes in Bilateria. Dev, Genes Evol. 212: 186-195.

Martindale MQ, Doe CQ, Morrill JB. 1985. The role of animal-vegetal interaction with respect to the determination of dorsoventral polarity in the equal-cleaving spiralian, $\mathrm{Lym}$ naea palustris. Roux's Arch. Dev. Biol. 194: 281-295.

Nederbragt AJ, van Loon AE, Dietus WJAG. 2002a. Hedgehog crosses the snail's midline. Nature 417: 811-812.

Nederbragt AJ, van Loon AE, Dictus WJAG. 2002b. Expression of Patella vulgata orthologs of engrailed and $d p p-B M P 2 /$ 4 in adjacent domains during molluscan shell development suggests a conserved compartment boundary mechanism. Dev. Biol. 246: 341-355.
Nederbragt AJ, te Welscher P, van den Driesche S, van Loon AE, Dietus WJAG. 2002c. Novel and conserved roles for orthodenticle/otx and orthopedia/otp orthologs in the gastropod mollusc Patella vulgata. Dev. Genes Evol. 212: 186 195.

Patten W. 1886. The embryology of Patella. Arb. Zool. Inst. Univ. Wien 6: 149-174.

Smith FGW. 1935. The development of Patella vulgata. Phil. Trans. Roy. Soc. London B 225: 95-125.

van den Biggelaar JAM. 1977. Development of dorsoventral polarity and mesentoblast determination in Patella vulgata. J. Morphol. 154: 157-186.

van den Biggelaar JAM, Guerrier P. 1979. Dorsoventral polarity and mesentoblast determination as concomitant results of cellular interactions in the mollusk Patella vulgata. Dev. Biol. 68: 462-471.

van der Koolj A, Nederbragt AJ, Goedemans HJ, van Loon AE. 1996. The stringlike genes of the limpet Patella vulgata. Gene 172: 261-265.

van der Kooij A, Veraart CP, van Loon AE. 1998. Cyclin A, cyclin $B$ and stringlike are regulated separately in cell cycle arrested trochoblasts of Patella vulgata embryos. Dev Genes Evol. 207: 524-534.

Verdonk NH, van den Biggelaar JAM. 1983. Early development and the formation of the germ layers. In: Verdonk NH, Van den Biggelaar JAM, Tompa AS, eds. The Mollusca, Development. Vol. 3, New York: Academic Press, 91-121.

Wanninger A, Haszprunar G. 2001. The expression of an engrailed protein during embryonic shell formation of the tusk-shell, Antalis entalis (Mollusca, Scaphopoda). Evol, Dev. 3: $312-321$.

Wanninger A, Rutherstein B, Lobenwein S, Salvenmoser W, Dictus WJAG, Haszprunar G. 1999. Development of the musculature in the limpet Patella (Mollusca, Patellogastropoda), Dev. Genes Evol. 209: 226-238.

Wilson EB. 1892. The cell-lineage of Nereis, A contribution to the cytogeny of the annelid body. J. Morphol. 6: 361-480.

Wilson EB. 1904. Experimental studies in germinal localization. II. Experiments on the cleavage-mosaic in Patella and Dentalium. J. Exp. Zool. 1: 197-268.

Received: 16 September 2002 